\title{
A word superiority effect with nonorthographic acronyms: Testing for unitized visual codes
}

\author{
HELGA NOICE and HOWARD S. HOCK \\ Florida Atlantic University, Boca Raton, Florida
}

\begin{abstract}
Letters in briefly presented masked letter strings were detected more accurately when the strings were three-consonant acronyms than when they were nonwords. In the absence of orthographic regularity, this word superiority effect (WSE) could not have depended on visual units corresponding to familiar bigrams. Since rendering the acronyms visually unfamiliar by alternating the case of their constituent letters did not introduce the left-right scanning effects observed for nonwords, it is concluded that the processing of the acronyms did not depend on the formation of whole-word visual units. It is argued instead that the WSE resulted from the postlexical activation of associatively connected single-letter codes. Finally, the results of case-alternation, sizealternation, and mixed-type-font experiments are interpreted in conjunction with the view that lexical access is based on both lowercase and uppercase letter recognition units for words and only uppercase letter recognition units for acronyms.
\end{abstract}

In Reicher's (1969) tachistoscopic recognition paradigm, the brief presentation of a test string (e.g., WORK) was preceded and followed by masking characters that interfered with the processing of the string. Subjects were then provided with two response alternatives (e.g., WORK-WORD). Their choice between the alternatives, which in the above example would indicate whether they had detected the presence of a $\mathrm{K}$ in the last letter of WORK, was better for strings that were words than for strings that were nonwords. This result, which has been termed the word superiority effect (WSE), indicates that tachistoscopic letter detection is facilitated by the activation of lexical entries for the test word.

Carr and Pollatsek (1985) have recently proposed that the WSE results from the formation of nonvisual, wholeword unitizing codes that "protect" the information in the briefly presented word from the effects of masking and memory loss. Evidence consistent with this hypothesis has been reported by Hawkins, Reicher, Rogers, and Peterson (1976), who showed that letter detection was more accurate for standard response alternatives (e.g., WORD-WORK) than for phonologically identical response alternatives (e.g., SITE-CITE). Another possibility is that the WSE could result from the formation of unitized whole-word codes that are visual rather than phonological. Experiments in which consecutive letters in a test string are presented in different cases (e.g., wOrK) are consistent with the hypothesis that higher order visual codes could mediate the WSE. Pollatsek, Well, and

The research reported in this paper was supported by Grant MDA90382-C-0317 from the Army Research Institute. We thank Mary LaLomia for preparing the computer programs used to conduct the experiments and analyze the data, and Edward O'Brien for his careful reading of the manuscript. Helga Noice is currently at Rutgers University. H. S. Hock's mailing address is Department of Psychology, Florida Atlantic University, Boca Raton, FL 33431.
Schindler (1975) found that case alternation increased the time required for subjects to detect letter differences between pairs of words but not between pairs of orthographically irregular nonwords. Although these results showed that case alternation could affect lexical activation by rendering words visually unfamiliar, McClelland (1976) found that the advantage of words over orthographically regular pseudowords was not affected by case alternation. This indicated that if visual unitization was responsible for the WSE, the units were smaller than the whole word. It is possible, however, that whole-word visual unitization was not observed in McClelland's study because lexical activation based on whole-word visual codes was less efficient than lexical activation based on phonological codes (formed by the application of spelling-to-sound translation rules to the orthographically regular words).

The purpose of the experiment reported in this paper was to determine whether a WSE could be obtained for the rapid, masked presentation of three-consonant acronyms (e.g., NBC). There were two reasons why the use of these acronyms provided a strong test of the visual unitization hypothesis. First, their shortness and the consistency with which they have been experienced in purely uppercase format increased the likelihood of the acronyms' being recognized (i.e., their lexical entries activated) on the basis of whole-word visual units. Second, the absence of vowels made it impossible for lexical activation to depend on whole-unit phonological codes formed via spelling-to-sound translation rules. In contrast, orthographically regular words are usually longer than acronyms, the likelihood of recognizing them on the basis of whole-unit visual codes is decreased because they are experienced in different case formats (sometimes all uppercase, sometimes all lowercase, sometimes with the first letter uppercase and the remaining letters lowercase), and they lend themselves to the formation of unitized phono- 
logical codes via spelling-to-sound translation rules. If lexical access depends on the relative efficiency of parallel phonological and visual processes (see Carr \& Pollatsek, 1985, for a review of parallel coding system models), there may be too many factors favoring the phonological channel for orthographically regular words.

Previous experiments have provided evidence for a WSE with acronyms (Egeth \& Blecker, 1971; Henderson, 1974), but the effect has been unreliable (Carr, Posner, Pollatsek, \& Snyder, 1979), subject to response bias (Henderson \& Chard, 1976; Seymour \& Jack, 1978), and dependent on whether the acronyms were presented to the left or right visual field (Besner, Davelaar, Alcott, \& Parry, 1984). However, most of the items used in these studies were at least partially orthographically regular (e.g., US in USA). We eliminated vowel-based orthographic combinations in our experiment in order to reduce the likelihood of partial spelling-to-sound translations, and because the presence of visually familiar bigrams might reduce the likelihood of subjects' activating lexical entries for the acronyms on the basis of whole-word visual units. The inconsistency of the WSE in previous studies using acronyms might have been due to subjects' forming intermediate-level visual codes that corresponded to orthographically familiar letter combinations within the acronyms (Glushko, 1979). The WSE would not be reliably obtained if lexical entries for the acronyms could not be activated through these intermediate-level codes.

A finding of superior letter-detection performance for the acronyms relative to three-consonant control strings would indicate that the WSE could be obtained in the absence of any orthographic regularity. Further evidence that the size of the WSE could be reduced by rendering the acronyms visually unfamiliar (via case alternation) would be consistent with the hypothesis that the WSE for acronyms depends on lexical activation via visual codes. However, the critical test for the whole-word visual unitization hypothesis would involve the effect of letter position on detection accuracy. If whole-unit visual codes were formed for the acronyms, (1) there should be little difference in detection accuracy between the first and third letter positions, and (2) case alternation should increase position effects by disrupting visual unitization.

\section{METHOD}

\section{Subjects}

The subjects were 36 Florida Atlantic University psychology students who participated in the experiment as one alternative toward fulfilling a course requirement. Each subject spoke English fluently and had normal or corrected-to-normal vision.

\section{Stimuli}

The 10 acronyms used in this experiment were all composed of three consonants (see Table 1). A preliminary study indicated that subjects recognized each of them (they were the 10 most familiar among a set of 30 three-consonant acronyms that were examined).

The first step in constructing the nonword control strings was to group the acronyms into pairs. For each pair, the first two letters of one acronym were combined with the third letter of the other
Table 1 Acronyms Used for the Experimental Trials

\begin{tabular}{ll} 
LSD & Lysergic Acid Diethylamide \\
NBC & National Broadcasting Company \\
LBJ & Lyndon Baines Johnson \\
FDR & Franklin Delano Roosevelt \\
JFK & John Fitzgerald Kennedy \\
PBS & Public Broadcasting System \\
CBS & Columbia Broadcasting System \\
FPL & Florida Power and Light \\
NFL & National Football League \\
BMW & Bavarian Motor Works \\
\hline
\end{tabular}

acronym or the last two letters of one acronym were combined with the first letter of the other acronym. Thus, pairing NBC with LSD yielded NBD and LBC as the nonword controls for NBC, and NSD and LSC as the nonword controls for LSD. The 10 acronyms were paired off in this manner to generate 20 nonword controls (Table 2). Using the same procedure, four more all-consonant acronyms (GNP, FTC, KGB, and CPR) were used to generate eight nonword controls for the practice list. For one group of subjects, all the letters were presented in uppercase. For a second group of subjects, all the strings were presented in alternating-case format (lowerupper-lower).

\section{Design}

The probe letter for each trial appeared equally often in the first and third positions. Half of the trials for each position were "yes" trials and half were "no" trials. Each acronym was tested in both the first and third positions. For NBC, the probe letter for the first position was $\mathrm{N}$ for "yes" trials and L for "no" trials; for the third position, the probe letter was C for "yes" trials and D for "no" trials. Each nonword-control string was tested in either the first or third positions, but not in both. As can be seen in Table 2, when the probe letter for testing a nonword-control string did not correspond to the letter being tested (a "no" trial), the probe letter in combination with the other two letters in the string formed one of the acronyms from which the nonword control was generated (e.g., the third-position "no" probe for NBD was C, which in combination with NB formed NBC). This feature of the design was the basis for testing familiarity bias in subjects' responses (further discussion of this test is presented in the Results section).

As can be seen in Table 2, there were two different nonwordcontrol strings for each acronym, but the total number of trials was the same for the acronyms (each was tested in two positions) and the nonword controls (each was tested in only one position). Since each position was tested twice, once with a "yes" probe and once with a "no" probe, each of the 10 acronyms was tested four times and each of the 20 nonword controls was tested twice, producing a total of 80 stimuli. Each subject worked on one of three orders (Latin square) of the three blocks. These 240 experimental trials were preceded by up to 96 practice stimuli, which constituted three blocks of 32 trials formed from the four practice acronyms and their eight nonword controls.

\section{Procedure}

Testing took place in a semidarkened, partially soundproof room. An Apple Ie microcomputer was used to present the stimuli and record the subjects' responses. A shield placed on the computer keyboard exposed two response keys (labeled "yes" and "no") and the "return" key. Each three-letter string was $0.5 \mathrm{~cm}$ in height and $1.2 \mathrm{~cm}$ in width. When viewed from a distance of $1.3 \mathrm{~m}$, each string subtended a visual angle of $0.2^{\circ}$ vertically and $0.5^{\circ}$ horizontally.

At the beginning of the experimental session, the experimenter told the subjects that they would be seeing three-letter strings, some of which would be meaningful and some of which would be 
Table 2

Items and Probe Letters for the Experimental Trials

\begin{tabular}{|c|c|c|c|c|c|}
\hline \multirow{2}{*}{\multicolumn{2}{|c|}{ Items }} & \multicolumn{4}{|c|}{ Test Letter } \\
\hline & & \multicolumn{2}{|c|}{ Yes Response } & \multicolumn{2}{|c|}{ No Response } \\
\hline Acronyms & Nonwords & Position 1 & Position 3 & Position 1 & Position 3 \\
\hline$\overline{\mathrm{LSD}}$ & $\begin{array}{l}\text { NSD } \\
\text { LSC }\end{array}$ & $\begin{array}{l}\mathbf{L} \\
\mathbf{N}\end{array}$ & $\begin{array}{l}\mathrm{D} \\
\mathrm{C}\end{array}$ & $\begin{array}{l}\mathbf{N} \\
\mathbf{L}\end{array}$ & $\begin{array}{l}\text { C } \\
\text { D }\end{array}$ \\
\hline NBC & $\begin{array}{l}\text { LBC } \\
\text { NBD }\end{array}$ & $\begin{array}{l}\mathbf{N} \\
\mathrm{L}\end{array}$ & $\begin{array}{l}\text { C } \\
\text { D }\end{array}$ & $\begin{array}{l}\mathbf{L} \\
\mathbf{N}\end{array}$ & $\begin{array}{l}\text { D } \\
\text { C }\end{array}$ \\
\hline LBJ & $\begin{array}{l}\text { FBJ } \\
\text { LBR }\end{array}$ & $\begin{array}{l}\mathrm{L} \\
\mathrm{F}\end{array}$ & $\begin{array}{l}\mathbf{J} \\
\mathbf{R}\end{array}$ & $\begin{array}{l}\text { F } \\
\text { L }\end{array}$ & $\begin{array}{l}\mathbf{R} \\
\mathbf{J}\end{array}$ \\
\hline FDR & $\begin{array}{c}\text { LDR } \\
\text { FDJ }\end{array}$ & $\begin{array}{l}\mathbf{F} \\
\mathbf{L}\end{array}$ & $\begin{array}{l}\mathbf{R} \\
\mathbf{J}\end{array}$ & $\begin{array}{l}\text { L } \\
\text { F }\end{array}$ & $\begin{array}{l}\mathbf{J} \\
\mathbf{R}\end{array}$ \\
\hline JFK & $\begin{array}{c}\text { PFK } \\
\text { JFS }\end{array}$ & $\begin{array}{l}\mathrm{J} \\
\mathrm{P}\end{array}$ & $\begin{array}{l}K \\
S\end{array}$ & $\begin{array}{l}\mathbf{P} \\
\mathbf{J}\end{array}$ & $\begin{array}{l}\mathbf{S} \\
\mathbf{K}\end{array}$ \\
\hline PBS & $\begin{array}{l}\text { JBS } \\
\text { PBK }\end{array}$ & $\begin{array}{l}\mathbf{P} \\
\mathbf{J}\end{array}$ & $\begin{array}{l}\mathbf{S} \\
\mathbf{K}\end{array}$ & $\begin{array}{l}\mathbf{J} \\
\mathbf{P}\end{array}$ & $\begin{array}{l}\mathbf{K} \\
\mathbf{S}\end{array}$ \\
\hline CBS & $\begin{array}{l}\text { FBS } \\
\text { CBL }\end{array}$ & $\begin{array}{l}\text { C } \\
\text { F }\end{array}$ & $\begin{array}{l}\mathbf{S} \\
\mathbf{L}\end{array}$ & $\begin{array}{l}\mathrm{F} \\
\mathrm{C}\end{array}$ & $\begin{array}{l}\mathbf{L} \\
\mathbf{S}\end{array}$ \\
\hline FPL & $\begin{array}{l}\text { CPL } \\
\text { FPS }\end{array}$ & $\begin{array}{l}\mathbf{F} \\
\mathbf{C}\end{array}$ & $\begin{array}{l}\mathbf{L} \\
\mathbf{S}\end{array}$ & $\begin{array}{l}\text { C } \\
\text { F }\end{array}$ & $\begin{array}{l}\mathbf{S} \\
\mathbf{L}\end{array}$ \\
\hline NFL & $\begin{array}{l}\text { BFL } \\
\text { NFW }\end{array}$ & $\begin{array}{l}\mathrm{N} \\
\mathrm{B}\end{array}$ & $\begin{array}{l}\text { L } \\
\text { W }\end{array}$ & $\begin{array}{l}\mathrm{B} \\
\mathbf{N}\end{array}$ & $\begin{array}{l}\text { W } \\
\mathbf{L}\end{array}$ \\
\hline BMW & $\begin{array}{l}\text { NMW } \\
\text { BML }\end{array}$ & $\begin{array}{l}\mathrm{B} \\
\mathrm{N}\end{array}$ & $\begin{array}{l}\text { W } \\
\text { L }\end{array}$ & $\begin{array}{l}\mathbf{N} \\
\mathbf{B}\end{array}$ & $\begin{array}{l}\mathbf{L} \\
\mathrm{W}\end{array}$ \\
\hline
\end{tabular}

meaningless. They were also told that a single letter would be presented immediately after each string, and that they were to decide whether or not the letter had appeared in the string in the same position as the test letter. The sequence of each trial was as follows. A fixation point in the center of the screen was replaced by three ampersands (\&\&\&), which were presented for $850 \mathrm{msec}$. The ampersands, in turn, were replaced by a three-letter string. After the string was presented (see below for the duration), the three ampersands replaced the string, along with a single probe letter beneath either the first or third position of the string. This display remained on the screen until the subject responded.

The experiment began with the presentation of up to 96 practice stimuli, half acronyms and half nonword controls. The subjects responded by pressing one of two keys (feedback was provided by a beep after an incorrect response). The practice trials involved a psychophysical staircase procedure, the purpose of which was to select an exposure duration for each subject that would result in his/her detection accuracy's reaching an asymptote of approximately $70 \%$ correct (this procedure ignored differences between the acronyms and nonwords). The staircase procedure resulted in the selection of an exposure duration for each subject that was used for all 240 experimental trials. The mean exposure duration was $88 \mathrm{msec}$ for strings presented entirely in uppercase and $98 \mathrm{msec}$ for strings presented in alternating case. The difference between the two conditions was not significant $[t(34)<1.0]$.

\section{RESULTS}

Mean percentage errors and $d^{\prime}$ scores for the experimental trials are presented in Table 3 . In the analyses of variance that follow, $F \mathrm{~s}$ refers to tests against error terms based on subject variability and $F i$ refers to tests against error terms based on item variability.

A WSE was obtained, but only when letter detection was tested in the third position of the three-letter strings. The results based on percentage errors indicated that there was a significant interaction between stimulus type and position $[F \mathrm{~s}(1,34)=30.01, p<.001, M S \mathrm{e}=11.82$; $F \mathrm{i}(1,9)=46.89, p<.001, M S \mathrm{e}=15.43]$. Similar results were obtained when the analysis was based on $d^{\prime}$ scores $[F \mathrm{~s}(1,34)=20.04, p<.001, M S \mathrm{e}=.41 ; F \mathrm{i}(1,9)$ $=44.85, p<.001, M S e=.12]$. Tests of simple effects (on percentage errors) indicated that the acronym/nonword difference (i.e., the WSE) was significant for the detection of letters in Position $3[F \mathrm{~S}(1,34)=27.56$, $p<.001, M S \mathrm{e}=13.33 ; F \mathrm{i}(1,9)=42.55, p<.001$, $M S e=15.54]$, but not for the detection of letters in Position $1\left[F_{\mathrm{S}}(1,34)<1.0 ; F \mathrm{i}(1,9)<1.0\right]$.

Case alternation reduced the size of the WSE by a factor of 2, the reduction being particularly evident when letter detection was tested in the third position. However, the effect of case alternation on the WSE was only marginally reliable. The interaction between stimulus type and case type on percentage errors was significant when tested against subject variability $[F \mathrm{~s}(1,34)=5.46, p<.05$, $M S e=29.66]$, but fell just short of significance when tested against item variability $[F \mathrm{i}(1,9)=4.27, p<.05$, $M S \mathrm{e}=34.13]$. When the analysis of variance was based on $d^{\prime}$ scores, the interaction fell just short of significance when items was the random factor $[F \mathrm{i}(1,9)=4.56, p>$ $.05, M S e=.44]$ and was not significant when subjects was the random factor $\left[F_{\mathrm{s}}(1,34)=2.69, p>.05, M S \mathrm{e}\right.$ $=.34]$. The marginal reliability of the case-alternation effect on the WSE could have been due to the fact that case alternation had its strongest effects when letter detection was tested for the first position but the WSE was

Table 3

Mean Percentage Error Rates, $d^{\prime}$ Scores, and Standard Errors

\begin{tabular}{|c|c|c|c|c|c|c|c|c|}
\hline \multirow{3}{*}{$\begin{array}{c}\text { Stimulus } \\
\text { Type }\end{array}$} & \multicolumn{4}{|c|}{ Uppercase } & \multicolumn{4}{|c|}{ Mixed Case } \\
\hline & \multicolumn{2}{|c|}{ Position 1} & \multicolumn{2}{|c|}{ Position 3} & \multicolumn{2}{|c|}{ Position 1} & \multicolumn{2}{|c|}{ Position 3} \\
\hline & Mean & $\overline{S E}$ & Mean & $\overline{S E}$ & Mean & $S E$ & Mean & $S E$ \\
\hline \multicolumn{9}{|c|}{ Percentage Errors } \\
\hline $\begin{array}{l}\text { Acronyms } \\
\text { Controls }\end{array}$ & $\begin{array}{r}8.1 \\
10.2\end{array}$ & $\begin{array}{l}1.1 \\
1.8\end{array}$ & $\begin{array}{l}10.4 \\
24.1\end{array}$ & $\begin{array}{l}1.6 \\
3.2\end{array}$ & $\begin{array}{l}16.7 \\
14.9\end{array}$ & $\begin{array}{l}2.2 \\
1.9\end{array}$ & $\begin{array}{l}13.6 \\
21.2\end{array}$ & $\begin{array}{l}2.1 \\
2.4\end{array}$ \\
\hline Difference* & 2.1 & & 13.7 & & -1.8 & & 7.6 & \\
\hline \multicolumn{9}{|c|}{$d^{\prime}$} \\
\hline $\begin{array}{l}\text { Acronyms } \\
\text { Controls }\end{array}$ & $\begin{array}{l}2.91 \\
2.84\end{array}$ & $\begin{array}{l}.20 \\
.21\end{array}$ & $\begin{array}{l}2.82 \\
1.60\end{array}$ & $\begin{array}{l}.19 \\
.21\end{array}$ & $\begin{array}{l}2.25 \\
2.30\end{array}$ & $\begin{array}{l}.23 \\
.20\end{array}$ & $\begin{array}{l}2.51 \\
1.81\end{array}$ & $\begin{array}{l}.21 \\
.20\end{array}$ \\
\hline Difference* & .07 & & 1.22 & & -.05 & & .70 & \\
\hline
\end{tabular}

Note-Standard errors are based on subject variance. *Word superiority effect. 
obtained only when letter detection was tested in the third position. ${ }^{1}$

The consistency of the WSE in Position 3 is highlighted by the $d^{\prime}$ data in Table 4; a positive WSE was obtained for each of the 10 acronyms. However, three of the items, FDR, NFL, and FPL, might be construed as having some residual orthographic regularity; the last two letters of each are orthographically regular bigrams. Their bigram regularity notwithstanding, we considered their occurrence irregular because DR, FL, and PL never appear in the final positions of words. However, to give our hypothesis the strongest possible test, we performed an additional analysis without these three items (and their associated nonword controls). Although there was an overall reduction in accuracy, the pattern of results and the outcome of statistical analyses remained the same.

The final analysis tested for familiarity bias. Henderson and Chard (1976) and Seymour and Jack (1978) found that subjects were biased to make "same" as opposed to "different" responses when the strings they were comparing were familiar acronyms as opposed to unfamiliar control strings. Carr et al. (1979) obtained a similar familiarity bias for orthographically regular words. For this reason, we tested for whether subjects were biased to respond "yes" when the probe letter combined with the previously detected information in the string to form a familiar acronym. Such a bias could have resulted in letter detection's being more accurate for the acronyms than for the control strings.

Our procedure for determining whether the WSE was due to familiarity bias was based on detection performance for the nonwords. Consider the string LBC. The probe letter for testing detection of the first letter in this string was either $\mathrm{L}$ or $\mathrm{N}$. The latter, combined with detected information specifying that there was a $B$ and a $C$, respectively, in the second and third positions of the string, could produce the familiar string, NBC. A higher rate of false alarms ("yes" responses to $N$ ) than misses ("no" responses to $\mathrm{L}$ ) would indicate that subjects were biased to respond "yes" when the probe letter completed a familiar acronym. However, this conclusion could be reached only in the absence of a general bias to make more

Table 4

The Word Superiority Effect for Each Acronym Obtained by Calculating the Difference in $d^{\prime}$ Between Each Acronym and Its Nonword Control Strings

\begin{tabular}{lrcccc}
\hline & \multicolumn{2}{c}{ Uppercase } & & \multicolumn{2}{c}{ Mixed Case } \\
\cline { 2 - 3 } \cline { 5 - 6 } & Position 1 & Position 3 & & Position 1 & Position 3 \\
\hline LSD & 1.79 & 2.93 & & -0.98 & 0.07 \\
NBC & 0.52 & 1.53 & & -0.80 & 0.88 \\
LBJ & 0.51 & 0.89 & & -0.31 & 0.85 \\
FDR & 0.00 & 2.24 & & 0.87 & 1.32 \\
JFK & -0.23 & 1.29 & & 0.94 & 0.94 \\
PBS & 0.32 & 1.60 & & 1.61 & 0.74 \\
CBS & 0.44 & 1.98 & & -0.76 & 0.71 \\
FPL & 0.66 & 1.70 & & -0.67 & 2.05 \\
NFL & -0.03 & 1.34 & & 0.70 & 0.53 \\
BMW & 0.13 & 0.63 & & -1.22 & 0.08 \\
\hline
\end{tabular}

"yes" than " no"' responses. In testing our nonword data for familiarity bias, we found that the false-alarm rate was equal to or lower than the miss rate at both probe positions and for both case types. In addition, there was no indication of a general bias toward "yes" responses (only $48.9 \%$ of the responses were "yes"). It was unlikely, therefore, that the WSE we obtained was the result of familiarity bias.

\section{DISCUSSION}

A potential problem in interpreting the results of the experiment involved the fact that each acronym was presented 12 times (letter detection was tested in both the first and third positions), whereas each nonword was presented 6 times (letter detection was tested in either the first or third position). Since previous experiments (e.g., Jacoby \& Witherspoon, 1982) have demonstrated that repetition effects can enhance word recognition, it might be argued that our data provided evidence for a repetition effect rather than a word superiority effect. There are two reasons for rejecting this argument. First, Smith (1979) has shown that repetition effects for consecutive presentations of a word are eliminated when subjects perform a letter detection task during the previous presentation of the word (as in the present study). Second, repetition tends to reduce rather than increase the effects of various stimulus variables on the processing of verbal materials. For example, Scarborough, Cortese, and Scarborough (1977) found that repetition decreased the effects of frequency of usage on lexical decision time and pronunciation time, and Kolers (1973) found that repetition decreased the difference in reading time between normal and inverted text. In an experiment more similar to the present study, Brooks (1977) showed that the difference in search time for words printed entirely in lowercase and words printed in alternating case decreased when the words were repeated. If the acronym advantage in our study had been due to repetition effects, the effect of case alternation on detection accuracy would have been smaller for the acronyms than for the nonwords, the reverse of the result we obtained. Baron and Thurston (1973) reached a similar conclusion when trying to determine whether their results, also obtained with the Reicher paradigm, were due to familiarity or repetition effects.

It was concluded, therefore, that the results obtained in this study were due to the effects of acronym familiarity on the accuracy with which the constituent acronym letters were detected. The absence of vowels for these stimuli made it impossible for the WSE to have depended on whole-unit phonological codes formed on the basis of spelling-to-sound translation rules. Furthermore, since the WSE did not require the presence of orthographically familiar spelling combinations, it could be concluded that if it depended on visual unitization, the units formed could not have corresponded to intermediate-level orthographically familiar bigrams (Glushko, 1979). Although evidence that letter position affected detection accuracy for 
the nonwords (implying left-right scanning) but not for the acronyms might be construed as indicating that wholeword visual units were formed for the acronyms, evidence inconsistent with the visual unitization hypothesis came from an examination of case-alternation effects. That is, case alternation reduced detection accuracy for the acronyms without introducing the left-right scanning effects obtained for the nonword data. If the WSE for the acronyms depended on the formation of whole-word visual units and case alternation was disrupting the formation of these units by rendering the acronyms visually unfamiliar, then left-right scanning effects would have been observed for the case-alternated acronyms (i.e., they would have been processed like the nonwords).

In the absence of evidence that the WSE depended on familiar whole-word visual units, and in view of the impossibility of its depending on familiar intermediate-level visual units, we concluded that the WSE obtained for the acronyms was mediated by the postlexical activation of higher order nonvisual units. These units could not have been formed as a result of spelling-to-sound translation rules; the acronyms lacked the vowels necessary for the application of such rules. We propose instead that they were based on codes corresponding to each letter in the acronym (Besner et al., 1984; McClelland, 1976), with unitization resulting from the postlexical activation of associative connections between the single-letter codes (as proposed by Adams, 1979).

One of the reasons Carr and Pollatsek (1985) argued that the WSE depended on the formation of higher order units was the need to protect the coded information in the briefly displayed strings from memory loss until the poststimulus response alternatives could be evaluated. If associative connections among single-letter codes were serving this function, it would be expected that the facilitative effects of familiarity would be observed for letters near or at the end of the string; these would be the letters most susceptible to being forgotten in a left-right scan of singleletter codes. This was the case in the experiment reported in this paper, as well as an unreported replication experiment (see again Note 1); a WSE was obtained for the acronyms, but only for the detection of letters in the third position.

The effect of case alternation in reducing the size of the WSE indicated that access to the lexicon was affected by the visual familiarity of the acronyms. But why does case alternation reduce the size of the WSE for acronyms (also reported by Besner et al., 1984) and not for orthographically regular words (McClelland, 1976)? As indicated earlier, orthographically regular words are experienced in a variety of ways, sometimes entirely lowercase, sometimes entirely uppercase, and sometimes with the first letter uppercase and the following letters lowercase. As a result, it is proposed that the lexical representations for orthographically regular words include recognition units for both the upper- and lowercase versions of their constituent letters. It would be for this rea- son that case alternation has no effect on the WSE for orthographically regular words. Because acronyms are experienced exclusively in uppercase, the lexical entries for acronyms would include recognition units for only the uppercase versions of their constituent letters. It would be because of the introduction of lowercase letters that case alternation reduces the WSE for acronyms (it may not eliminate it because lexical activation could still occur via letter-level phonological codes). Alternating the size of consecutive uppercase letters would not affect the WSE for acronyms (Besner et al., 1984) if the recognition units for the uppercase letters specified the attributes for recognizing the letters with sufficient abstraction for the recognition units to generalize to letters of any size. A similar argument would account for the invariance of the WSE when words are presented in mixed typefaces (Adams, 1979).

In conclusion, the results of this experiment indicated that a WSE could be obtained in the Reicher paradigm in the absence of orthographic regularity. However, there was no support for the hypothesis that the WSE for acronyms was mediated by whole-word visual codes. If evidence for whole-word visual unitization could not be obtained for three-consonant acronyms, it is unlikely that such evidence would be obtainable for orthographically regular words. It is possible, of course, that evidence for visual unitization might be obtained with another experimental paradigm. For example, Carr, Pollatsek, and Posner (1981) have argued that the same-different matching task is more likely to involve visual coding than the Reicher tachistoscopic recognition task, which is more likely to emphasize phonological coding. Another possibility is that by requiring the detection of a target letter within each string, Reicher's tachistoscopic recognition paradigm may place too much emphasis on letter-level coding for visual unitization to occur. Associative unitization may be functionally advantageous in the Reicher paradigm because it allows for both the letter-level coding emphasized by the letter detection task and the unitization required to protect, from memory loss, the coded information in the briefly displayed strings. The conclusion that the WSE obtained in this study was due to associative unitization is not necessarily inconsistent with Carr and Pollatsek's (1985) assertion that unitization in the WSE is typically phonological. In the case of threeconsonant acronyms, phonological unitization cannot be based on the application of spelling-to-sound translation rules to orthographically regular letter strings, but it remains possible that the lexical representation of the acronyms involves associative connections among letter-level phonological units.

\section{REFERENCES}

Adams, M. J. (1979). Models of word recognition. Cognitive Psychology, 11, 133-176.

Baron, J., \& ThuRSTON, I. (1973). An analysis of the word-superiority effect. Cognitive Psychology, 4, 207-228. 
Besner, D., Davelaar, E., Alcott, D., \& Parry, P. (1984). Wholistic reading of alphabetic print: Evidence from the FDM and the FBI. In L. Henderson (Ed.), Orthographies and reading: Perspectives from cognitive psychology, neuropsychology and linguistics. Hillsdale, $\mathrm{NJ}$ : Erlbaum.

Brooks, L. (1977). Visual pattern in fluent word identification. In A. S. Reber \& D. L. Scarborough (Eds.), Toward a psychology of reading. Hillsdale, NJ: Erlbaum.

CARR, T. H., \& Pollatsek, A. (1985). Recognizing printed words: A look at current models. In D. Besner, T. G. Waller, \& G. E. MacKinnon (Eds.), Reading research: Advances in theory and practice (Vol. 5). Orlando, FL: Harcourt, Brace, Jovanovich.

Carr, T. H., Pollatsek, A., \& Posner, M. I. (1981). What does the visual system know about words? Perception \& Psychophysics, 29, 183-190.

Carr, T. H., Posner, M. I., Pollatsek, A., Snyder, C. R. R. (1979). Orthographic and familiarity effects in word processing. Journal of Experimental Psychology: General, 108, 389-414.

EGETH, H., \& BLECKER, D. (1971). Differential effects of familiarity on judgments of sameness and difference. Perception \& Psychophysics, 9, 321-326.

GLushko, R. J. (1979). The organization and activation of orthographic knowledge in reading aloud. Jourmal of Experimental Psychology: Human Perception \& Performance, 5, 674-691.

Hawkins, H. L., Reicher, G. M., Rogers, M., \& Peterson, L. (1976). Flexible coding in word recognition. Joumal of Experimental Psychology: Human Perception \& Performance, 2, 380-385.

HENDERSON, L. (1974). A word superiority effect without orthographic assistance. Quarterly Journal of Experimental Psychology, 26, 301-311.

Henderson, L., \& Chard, J. C. (1976). On the nature of the facilitation of visual comparisons by lexical membership. Bulletin of the Psychonomic Society, 7, 432-434.

JACOBY, L. L., \& WITHERSPOON, D. (1982). Remembering without awareness. Canadian Journal of Psychology, 36, 300-324.

Kolers, P. A. (1973). Remembering operations. Memory \& Cognition, 1, 347-355.

McClelland, J. L. (1976). Preliminary letter identification in the perception of words and nonwords. Journal of Experimental Psychology: Human Perception \& Performance, 2, 80-91.
Pollatsek, A., Well, A. D., \&Chindler, R. M. (1975). Familiarity affects visual processing of words. Journal of Experimental Psychology: Human Perception \& Performance, 1, 328-338.

Reicher, G. M. (1969). Perceptual recognition as a function of meaningfulness of stimulus material. Journal of Experimental Psychology, 81, 275-280.

Scarborough, D. L., Cortese, C., \& Scarborough, H. S. (1977). Frequency and repetition effects in lexical memory. Journal of Experimental Psychology: Human Perception \& Performance, 3, 1-17.

SeYmouR, P. H., \& JACK, M. V. (1978). Effects of visual familiarity on "same" and "different" decision processes. Quarterly Journal of Experimental Psychology, 30, 455-469.

SMITH, M. C. (1979). Contextual facilitation in a letter search task depends on how the prime is processed. Journal of Experimental Psychology: Human Perception \& Performance, 5, 239-251.

\section{NOTE}

1. The results reported in this experiment were replicated as one part of another experiment. In this replication, which included two more acronyms (BLT, VHF) and their associated nonword controls, the WSE was again obtained only when letter detection was tested in the third position. Analyses of variance on percentage errors replicated the significant interaction between stimulus type and position $[F \mathrm{~s}(1,34)=28.76$, $p<.001, M S e=33.06 ; F \mathrm{i}(1,11)=12.41, p<.05, M S e=110.59]$. Tests of simple effects indicated that the acronym/nonword difference in letter detection accuracy was significant for Position $3[F \mathrm{~s}(1,34)=$ 45.33, $p<.001, M S e=37.32 ; F \mathrm{i}(1,11)=19.83, p<.01, M S \mathrm{Se}=$ 120.25], but not for Position $1[F \mathrm{~s}(1,34)=2.34, p>.05, M S e=$ $37.23 ; F \mathrm{i}(1,11)=1.10, p>.05, M S e=120.25]$

Case alternation again reduced the size of the WSE, and the reduction was again greater when letter detection was tested in the third position. However, in this experiment the effect of case alternation on the WSE was statistically reliable: the interaction between stimulus type and case type on percentage errors was significant $\left[F_{\mathrm{s}}(1,34)=15.10\right.$, $p<.001, M S \mathrm{e}=41.39 ; F \mathrm{i}(1,11)=8.92, p<.05, M S \mathrm{e}=100.26]$.

(Manuscript received March 17, 1987; revision accepted for publication May 18, 1987.) 